\title{
Morphological, Chemical and Electrical Characterization of a Family of Commercial Nanofiltration Polyvinyl Alcohol Coated Polypiperazineamide Membranes
}

\author{
A. Otero-Fernández ${ }^{a}, P$. Díaz $^{b}, J_{\text {.A. Otero }}^{c}$, R. Ibáñez $^{b}$, A. Maroto-Valiente $^{a}$, \\ L. Palacio ${ }^{d}, P$. Prádanos ${ }^{d}$, F.J. Carmona ${ }^{d}$ and A. Hernández ${ }^{d^{*}}$
}

\begin{abstract}
${ }^{a}$ Departamento de Química Inorgánica y Química Técnica, Facultad de Ciencias, Universidad Nacional de Educación a Distancia (UNED), 28040 Madrid, Spain.

${ }^{c}$ Grupo de Ingeniería de Procesos de Filtración con Membranas (IPFM), Depto.de Ingeniería Química y Biomolecular. E.T.S. de Ingenieros Industriales y Telecomunicación. Universidad de Cantabria, 39005 Santander, Spain.

${ }^{b}$ Grupo de Ingeniería de procesos sostenibles. Depto. de Ingeniería Química y Biomolecular, E.T.S. de Ingenieros Industriales y Telecomunicación, Universidad de Cantabria, 39005 Santander, Spain.

${ }^{d}$ Grupo de Superficies y Materiales Porosos (SMAP), Dpto. de Física Aplicada, Facultad de Ciencias, Universidad de Valladolid, 47011, Valladolid, Spain.

*Author to whom correspondence should be addressed.
\end{abstract}

\begin{abstract}
Three AFC membranes from PCI, of the thin film composite (TFC) nanofiltration type, have been characterized by using XPS, AFM, Contact angles, Zeta potential and permeation experiments. This plethora of complimentary methods portrays a deep and exhaustive description of these membranes.
\end{abstract}

Morphological properties, including porosity, water permeability, fractal dimension, Wenzel parameter and roughness, correlate well with pore sizes. While functional characteristics as, for example wettability correlate well with the $\mathrm{O} / \mathrm{N}$ ratio. Increasing $\mathrm{O} / \mathrm{N}$ ratios should be interpreted as caused by increasing PVA coverages.

The charge on the membrane's surface is ordered in a different way for different $\mathrm{pH}$ but are quite similar anyway. The effect of charges on retention of 1:1, 1:2 and 2:1 salts (as tested with: $\mathrm{NaCl}, \mathrm{Na}_{2} \mathrm{SO}_{4}$ and $\mathrm{CaCl}_{2}$ ) increases with increasing $\mathrm{O} / \mathrm{N}$ and wettability. Consequently, the trend of salt retentions can be explained in terms of the PVA coverage and the details of the amphoteric behavior of the three AFC membranes studied.

\section{Keywords:}

Nanofiltration; Surface charge; Surface morphology; Wettability; Salt retention. 


\section{Introduction}

Recently, nanofiltration (NF) has been extensively used in many water, chemical and biotechnological applications due to its ease of operation, as compared to the conventional processes and other membrane separation techniques [1]. NF has lower costs due to the relatively low operating pressures that it requires. This leads also to low energy consumption and to cutbacks in both pressure pumping and piping costs [1]. The effectiveness of NF membranes depends on many factors including: the charge density on the membrane surface; the geometry of the membrane module; its configuration and its mode of operation. Of course, it depends, as well, on the operating pressure, temperature, $\mathrm{pH}$, feed flow, concentration and other factors [2].

Nanofiltration membranes have been manufactured in quite different ways, although, certainly, polymeric membranes are dominant [3, 4]. Especially, thin film composite (TFC) membranes have experienced a tremendous development since the concept of interfacial polymerization was first introduced by Morgan in 1965 [5] and eventually reached a history of success [6]. Some evolution of the concept appeared including, for example, thin film nanocomposite membranes (TFN) [7]. Currently, the use of TFC membranes dominates the applications of NF and RO and has showed a huge potential to be further used in applications involving gas separation, pervaporation, etc. Nevertheless, it is too early to conclude that this technology has already reached its maturity, because many opportunities remain still open [6, 7].

Here we will study AFC nanofiltration membranes manufactured from PCI and specifically the AFC 30, 40 and 80 series. These membranes have been used in many industrial separation applications including heavy metals rejection from water effluents [8-13]. Other contaminants and salts have also been rejected $[14,15]$ and they have been used also in food industries [16,17] and the retention of pharmaceuticals [18]. Our aim here is to analyze the AFC nanofiltration membranes from the point of view of their material properties, attending to their physico-chemical, morphological, electric and hydrophilic properties by using a plethora of methods and correlating these material properties with their flux and retention features.

\section{Experimental}

\subsection{Membranes and Chemicals}

As mentioned, we will study here three nanofiltration membranes of the same commercial series, AFC30, AFC40 and AFC80, of the "thin film composite" type. These membranes are supposed to have active layers made of an aromatic polyamide supported on a polysulfone substrate. Each of these tubular membranes is used arranged as a bunch of 18 tubes connected in series inside a stainless steel module of the B1 type AISI 316. The membrane tubes have an inner diameter of $12.73 \cdot 10^{-3} \mathrm{~m}$ and a length of $1.2 \mathrm{~m}$. The membranes are connected in series giving a total length of $21.60 \mathrm{~m}$ and a total filtration area, per module, of $0.864 \mathrm{~m}^{2}$. Both module and membranes were provided by PCI (PCI membranes a division of Xylem, White Plains, New York, USA). 


\subsection{XPS}

An X-ray Photoelectron Spectroscopy (XPS) device ESCA PROBE P made by Omicron (Omicron Nanotechnology, Taunusstein-Neuhof, Hesse, Germany) has been used. The device is provided with an EA-125 energy analyzer with 7 chanels (2.200 eV) and a $\mathrm{X}$ ray source with $\mathrm{Mg}$ and $\mathrm{Al}$ anodes. We have used the $\mathrm{Mg}$ anode in our experiments.

A semi-quantitative analysis of the elemental composition is possible by using the peak areas as:

$\frac{M_{i}}{M_{j}}=\frac{\left(I_{i} / S_{i}\right)}{\left(I_{j} / S_{j}\right)}$

$I_{i}$ is the area of the peak for the i-th element and $S_{i}$ is its sensibility factor. Of course, this can be done after an appropriate base line correction has been performed. The sensibility factor depends on several element and apparatus characteristics. Fort the C1s, O1s and N1s peaks $S_{i}$ of $1,2.85$ and 1.77 have been considered.

Moreover, the chemical states of elements can be studied by attending to their exact positions, separation and profiles. Peaks can be de-convolved into an appropriate mixture of Lorentz and Gaussian peaks corresponding to the different chemical states of a given element. Here the CASA XPS software (Casa Software Ltd, Teignmouth, Devon, UK) has been used and the $\mathrm{C} 1 \mathrm{~s}(\mathrm{~Eb}=284.6 \mathrm{eV})$ peak was used as calibration point for shifts. Some details on the XPS analysis and databases for polymers can be seen in the literature $[19,20]$.

\subsection{Zeta potential}

A SurPASS Electrokinetic Analyzer (Anton Paar GmbH, Graz, Austria) has been used to measure the streaming potential $v_{p}=\Delta \Phi / \Delta p$ inside the tubular membranes lumen. The device converts streaming potential to zeta potential $\boldsymbol{\zeta}$. Both these magnitudes were measured at different $\mathrm{pH}$ within the range 2 to 9 by using $\mathrm{HCl}$ or $\mathrm{NaOH}$ droplets as required. The measurements were done for $10^{-3} \mathrm{M} \mathrm{KCl}$ solutions.

\subsection{AFM and pore sizes}

Atomic Force Microscopy (AFM) has been performed with a Nanoscope Multimode IIIa scanning probe microscope from Digital Instruments (Veeco Metrology Inc., Santa Barbara, California, USA). AFM images allow the visualization of a surface at different magnifications depending on the scan size of the image. Such images are stored as an array of $\mathrm{x}, \mathrm{y}$, and $\mathrm{z}$ strings, which makes it easy to obtain other parameters related to the surface that can be useful for their quantitative analysis. The average $\left(R_{a}\right)$ and the root mean squared $\left(\mathrm{R}_{\mathrm{q}}\right)$ roughness and pore size distributions can be obtained directly for different AFM explored areas by using an appropriate tool for image analysis. The AFM images were processed by using a fast Fourier transform (FFT) filtering procedure $[21,22]$ in order to isolate, as much as possible, pore entrances. 
The so called E scanner (horizontal and vertical ranges of 10 and $2.5 \mu \mathrm{m}$, respectively) has been used here. The scanned areas have gone from $40 \times 40 \mathrm{~nm}$ to $10 \times$ $10 \mu \mathrm{m}$. The smallest areas of $40 \times 40 \mathrm{~nm}$ have only been used to get the accurate optimal resolution to detect the pore entrances. For scanned areas over $10 \times 10 \mu \mathrm{m}$ scratches and other surface damages would be apparent.

Roughness for self-similar surfaces can be characterized by their fractal dimension, which can be evaluated from AFM results by using the corresponding power spectra density function $\gamma(\vec{\sigma})$ which corresponds to the bi-dimensional roughness spectra and allows to evaluate the fractal dimension as [23]:

$D_{f}=\frac{8-n}{2}$

Where $n$ is the slope of the function $\gamma(\vec{\sigma})$ in a double logarithmic scale.

Other coefficient of interest, mainly in conection with contact angles, is the relationship between the real area $\left(A_{s}\right)$ and the projected area $\left(A_{p}\right)$ of the surface:

$$
r_{W}=\frac{A_{s}}{A_{p}}
$$

This ratio can be called the Wenzel factor.

\subsection{Contact Angles}

Water contact angles were measured by a static procedure, which was carried out by the sessile drop method using a goniometer (FTA 200, Portsmouth, Virginia, USA). Contact angle was measured from digitized pictures by using an "ad-hoc" software of analysis. A drop of deionized water was added by a motor-driven syringe at $298.15 \mathrm{~K}$. it is worth noting that the influence of roughness on contact angle can be taken into account by assuming that the actual material contact angle $\theta$ is not equal to the apparent one $\theta_{a p p}$ but $[24,25]$ :

$$
\cos \theta=\frac{\cos \theta_{a p p}}{r_{W}}
$$

\subsection{Permeation Plant}

Permeation experiments were performed in a semi-industrial pilot plant, designed and constructed by the Group of Membrane Filtration Processes Engineering of the Universidad de Cantabria (IPFM-UC-Spain)) [26], and shown schematically in Figure 1. The plant is provided with a motor pump covering a wide range of pressures from microfiltration (MF) to reverse osmosis (RO). Within this plant, three membrane modules of the B1 type were inserted with the AFC30, AFC40 or AFC80 membranes inside. Both permeate and concentrated were returned to the feed tank to maintain stationary conditions. Pressures up to $4 \mathrm{MPa}$ were used with a high feed cross flow of $1600 \mathrm{~L} / \mathrm{h}$ at a temperature of $30{ }^{\circ} \mathrm{C}$. Isotonic $\mathrm{NaCl}, \mathrm{Na}_{2} \mathrm{SO}_{4}$ and $\mathrm{CaCl}_{2}$ concentrations were used, namely: $0.01 \mathrm{M}$ for $\mathrm{NaCl}, 0,00769 \mathrm{M}$ for $\mathrm{Na}_{2} \mathrm{SO}_{4}$ and 0,0073 $\mathrm{M}_{\text {for }} \mathrm{CaCl}_{2}$. The resulting 
natural $\mathrm{pH}$ was approximately neutral (in the 6.5 to 7 range). Concentrations were measured by using an HQ40D Portable Multi Meter with a conductivity (CDC401) probe, $\mathrm{pH}$, Conductivity, IntelliCAL Hach Compay (Loveland, Co, USA). The same multi-meter with an appropriate probe (PHC 101) is used to measure $\mathrm{pH}$. Concentrations were occasionally tested by comparison to those measured by inductively coupled plasma atomic emission spectroscopy (ICP-AES) with an Agilent 720 ICP Optical Emission Spectrometer (Agilent Technologies, Santa Clara, California, US).

Prior to any experiment, the used membranes were stabilized during at least $1-2 \mathrm{~h}$ at the maximal working pressure of $4 \mathrm{MPa}$. The corresponding water permeability was measured between each single experiment and cleaning was performed if necessary until the original water permeability was restored. Cleaning was done by permeating P3Ultrasil53 solutions in concentrations from 0.2 to $1 \% \mathrm{w} / \mathrm{w}$ at $40{ }^{\circ} \mathrm{C}$.

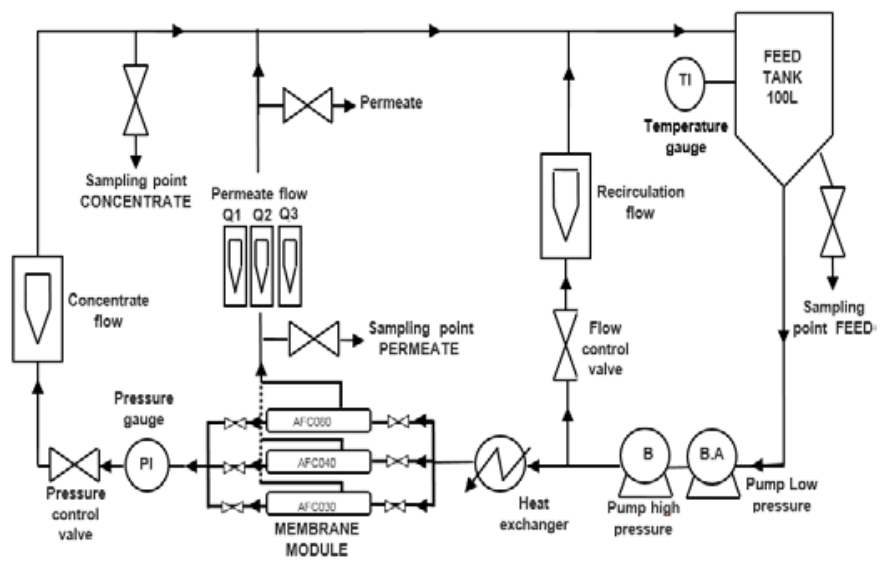

Fig. 1.- Scheme of the permeation plant used.

\subsection{Retention}

The retention coefficient can be evaluated as:

$$
R_{t}=1-\frac{c_{p}}{C_{m}}
$$

Here $\boldsymbol{c}_{\boldsymbol{p}}$ is the concentration of the permeate, while $\boldsymbol{c}_{\boldsymbol{m}}$ is the concentration in close contact with the feed side of the membrane. This $R_{t}$ is customarily called true retention coefficient. Nevertheless, it is worth noting that the only directly accessible retention coefficient is the observed retention coefficient:

$$
R_{O}=1-\frac{c_{p}}{c_{f}}
$$

This coefficient includes $\boldsymbol{c}_{\boldsymbol{f}}$, the feed concentration, instead of $\boldsymbol{c}_{\boldsymbol{m}}$.

According to the film layer model for concentration polarization, $\mathrm{c}_{\mathrm{m}}$ is given by:

$$
c_{m}=c_{p}+\left[c_{f}-C_{p}\right] e^{J_{v} / K_{m}}
$$


The mass transfer coefficient, $\mathrm{K}_{\mathrm{m}}=\mathrm{D} / \delta$ (with $\mathrm{D}$ the diffusivity of the solute and $\delta$ the thickness of the concentration-polarization layer) could be evaluated by using an adequate correlation of dimensionless numbers (Sh, Re and Sc, Sherwood, Reynolds and Schmidt numbers respectively) as:

$$
\mathrm{Sh}=A(\mathrm{Re})^{\alpha}(\mathrm{Sc})^{\beta}
$$

with:

$$
\operatorname{Re}=v^{\prime} \rho d_{h} / \eta, \quad S c=\eta / \rho D, \quad S h=K_{m} d_{h} / D
$$

$v$ is the mean speed in along the feed channel and $d_{h}$ is its hydraulic diameter. The feed fluid has a density $\rho$ and a viscosity $\eta$, that can be approximated by those of pure water with errors below $0.2 \%$ [27]. A, $\alpha$ and $\beta$ depend on the referred dimensionless numbers.

In our experimental conditions, we have $6000<\mathrm{Re}<21000$ with $900<\mathrm{Sc}<1100$ (with

$d_{h}=12.73 \cdot 10^{-3} \mathrm{~m}$ corresponding to the inner diameter of the tubular membranes). In these circumstances, the Chilton-Colburn ( $A=0.023, \alpha=4 / 5$ and $\beta=1 / 3$ ), Prandtl-Taylor $(A=0.34, \quad \alpha=0.75$ and $\beta=1 / 3)$ or Harriot-Hamilton ( $A=0.0096, \quad \alpha=0.91$ and $\beta=0.35)$ correlations [28, 29] have been advised in the literature [30]. Once $\alpha$ is known, we can reorder Eqs. (7) and (8) to get:

$$
\begin{aligned}
& \mathrm{K}_{m}=\phi v^{\alpha} \\
& \phi=A D^{1-\beta} d_{h}^{\alpha-1}\left(\frac{\rho}{\eta}\right)^{\alpha-\beta}
\end{aligned}
$$

Then Eq. (6) can be written as [31]:

$$
\ln \frac{R_{0}}{1-R_{0}}=\ln \frac{R_{t}}{1-R_{t}}+\frac{1}{\phi}\left(\frac{J_{V}}{v^{\alpha}}\right)
$$

This would allow obtaining $\ln R_{t} /\left(1-R_{t}\right)$ from a plot of $\ln R_{0} /\left(1-R_{0}\right)$ against $J_{V} / \nu^{\alpha}$. Of course this procedure would only be possible if $\alpha$ is previously known and the experimental conditions make $\ln R_{t} /\left(1-R_{t}\right)$ constant. $\ln R_{t} /\left(1-R_{t}\right)$ would be, at least approximately, constant when $\mathrm{C}_{\mathrm{m}}$ is high enough as to give fluxes not depending on $\Delta p$, which is not our case, because then the flux would be mainly convective. It would be also nearly constant when fluxes are low enough as to correspond to mainly diffusive conditions with a linear increase of $c_{p}$ with $c_{m}$ which is very nearly true in our experimental conditions [30].

\section{Results and Discussion}

\subsection{XPS Analysis}

The corresponding percentage abundances of the elements detected on the surface of the membranes by XPS are shown in Table I. 


\begin{tabular}{ccccccc}
\hline \multicolumn{7}{c}{ Table l.- XPS elemental percentages. (ref. to the global amount). } \\
\hline Membrane & \% C & \% O & \% N & O/C & N/C & O/N \\
\hline AFC30 & 65.83 & 32.27 & 1.90 & 0.490 & 0.029 & 16.949 \\
\hline AFC40 & 69.11 & 23.70 & 7.19 & 0.343 & 0.104 & 3.290 \\
\hline AFC80 & 67.92 & 25.48 & 6.60 & 0.375 & 0.097 & 3.861 \\
\hline
\end{tabular}

Tang and coworkers represented the $\mathrm{O}$ content versus the $\mathrm{N}$ one with lines corresponding to aromatic and linear polyamides and they extracted valuable information on some polyamide membranes and their coatings by using the kind of representation [32] used in Figure 2. Some other membranes taken from literature are also shown there for the sake of comparison. In Figure 2a, light and dark gray circles correspond to those already shown by Tang and coworkers [32-34]. Light gray squares correspond to several $\gamma$-irradiated membranes [35, 36]. Gray diamonds correspond to chlorinated RO membranes [37]. Wei and coworkers grafted a RO membrane with 3-allyl-5,5dimethylhydantoin (ADMH) [38], the corresponding series for increasing grafting times is shown in Figure 2b. Our membranes are also shown in the figure as blue circle symbols. Note that they fit well to a progressive high polyvinyl alcohol (PVA) coverage of polypiperazineamide (PPA) aromatic material. Hollow symbols correspond to linear and aromatic polyamide (PA) and polypiperazineamides (PPA) [32, 39-41].

Trimesoyl chloride (TMC) and piperazine (PIP) are two of the most extensively used monomers for formulating TFC NF membranes that have active layers with polypiperazineamide [42, 43]. An et al. [44] introduced PVA as a co-additive with PIP during its interfacial polymerization with TMC and analyzed the resulting NF membranes by XPS and other methods. The corresponding $\mathrm{N}-\mathrm{O}$ plot is also included in Figure 2b (light blue circles) and fits well with the postulated straight, from aromatic PPA (TMCPIP) to PVA representative points, fitted to our membranes. It is worth mentioning that different conditions of synthesis [45] and different substrates could give slightly different XPS results [46, 47]. Note that light blue and red X-shaped symbols are experimental while dark blue one is a hypothetical extrapolated representation of the un- treated base material for the AFC membranes.
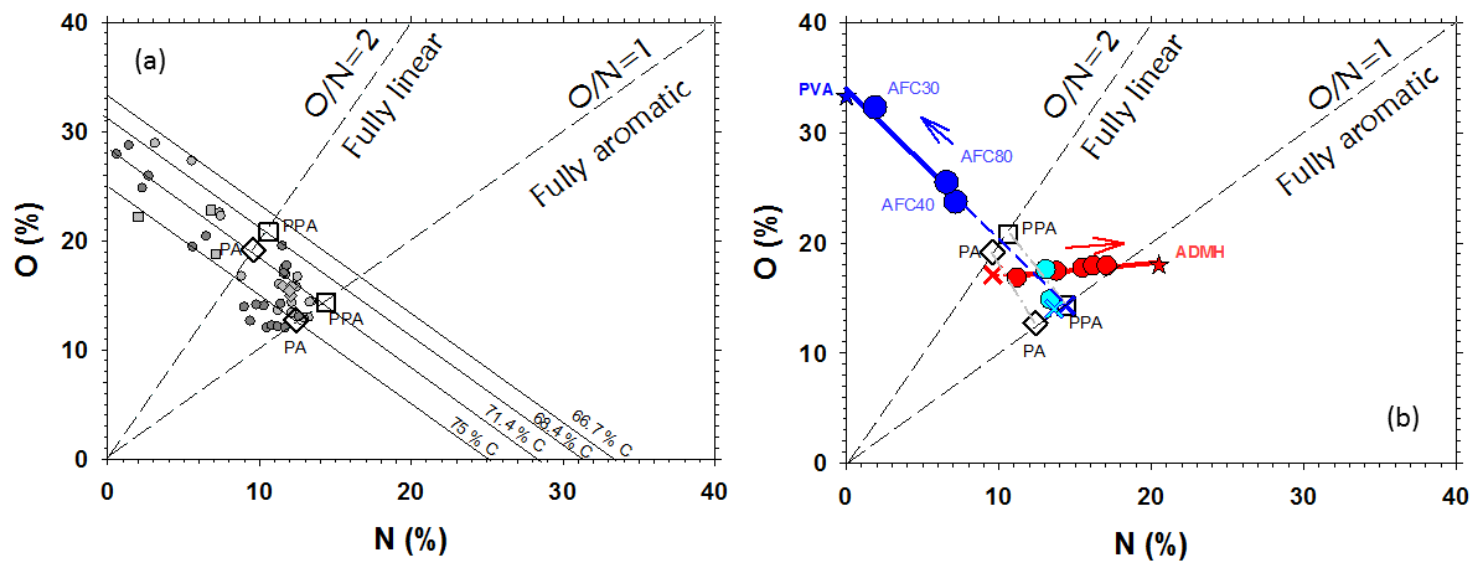

Fig. 2.- $O$ versus $N$ content of some $R O$ and $N F$ polyamide-like membranes taken from literature (a). Our membranes (large blue circles) and others are shown too (b). For more details, see the text. 
Negative surface charge density can be generated by deprotonation of carboxylic groups $\left(\mathrm{COOH} \rightarrow \mathrm{COO}^{-}\right)$while positive charge density can result from the protonation of amine groups ( $\mathrm{NH}_{2} \rightarrow \mathrm{NH}_{3}{ }^{+}$) [48]. Negative charge densities can also be generated from PVA because, in addition to the hydroxyl groups $(-\mathrm{OH})$, the PVA macromolecules contain a small number of acetate groups (-O-COCH3) [49]. These groups could remain in the polymer chains as a result of incomplete alcoholysis giving carboxyl $\mathrm{C}(=\mathrm{O}) \mathrm{OH}$ and carbonyl $\mathrm{C}=\mathrm{O}$ groups [50]. These groups can also be caused by crosslinking of PVA, for example by glutaraldehyde and/or maleic acid [51], although many others crosslinkers have been used as other aldehydes, dialdehydes and maleic, succinic, suberic, malic or other acids (see Figure 3).

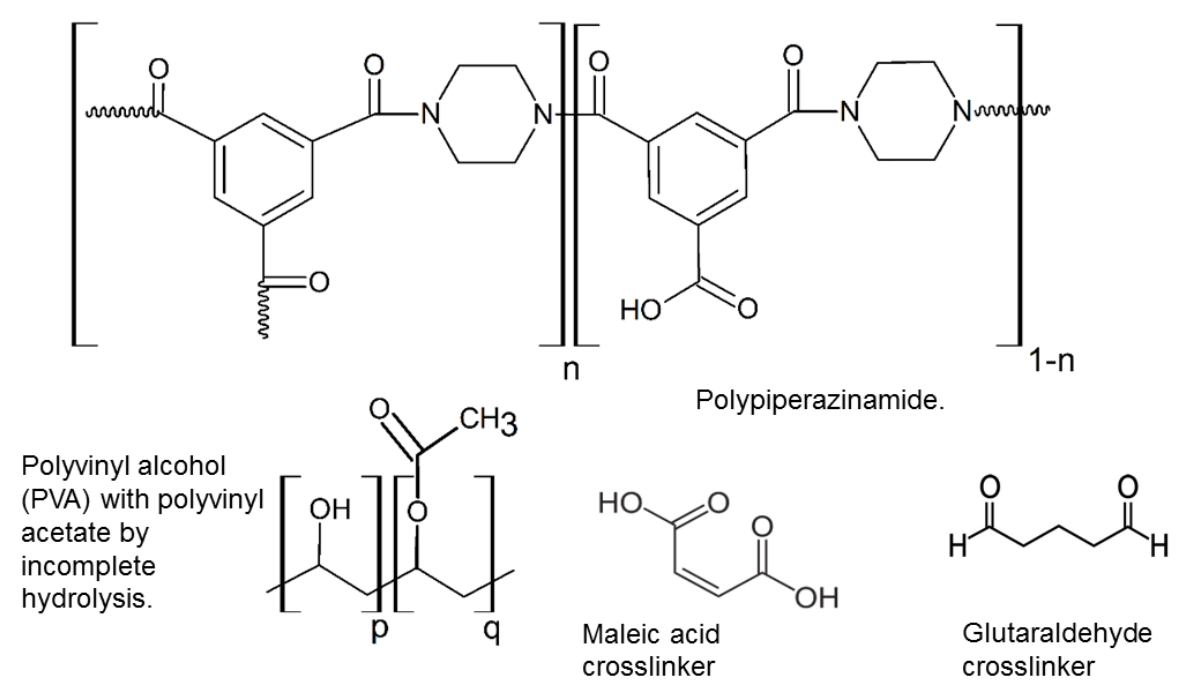

Fig. 3.- Polypiperazinamide, PVA and some of the usual crosslinkers.

It is worth mentioning that PVA is classified as a nonionic polymer that, even when containing reasonable amounts of ionizable acetate groups, cannot induce noticeable changes in the isoelectric point, IPE. It should be also added that negative charge of poly(vinyl alcohol chains) is due to the existence of resonant structure of polymer macromolecule and migration of partial negative charge from the $\left(-\mathrm{CH}_{2}\right)$-groups located at $\alpha$ positions relative to the acetate groups to carbonyl oxygen of the acetate group (and conversely). This dispersion of negative charge on various chain fragments would make its influence on the solid surface charge density minimal according to Wiśniewska et al. $[42,52]$ that worked on inorganic membranes. Tang et al. [33] commented, for other polyamide membranes, that uncoated membranes, with amide groups, show much higher surface zeta potential, giving greater isoelectric points than those coated ones. This should be due, according to them, to the presence of negative charges caused by the coating films containing oxygen atoms mainly associated with hydroxyl, carboxyl and carbonyl groups. Pan et al. proved that the addition of certain co-reactive as sericin, increasing $\mathrm{O} / \mathrm{N}$ ratio, can modulate the resulting surface charges to make PIP-TMC membranes more negative changing the IEP from 4.7 to 3.7 [53].

It seems that AFC membranes should have negative charges ordered according to their $\mathrm{O} / \mathrm{N}$ ratio, $\phi_{\mathrm{O} / \mathrm{N}}$, that, as seen in Table I and Figure 2, is: 


$$
\phi_{\mathrm{O} / \mathrm{N}}^{\mathrm{AFC} 30}>\phi_{\mathrm{O} / \mathrm{N}}^{\mathrm{AFC} 80} \geq \phi_{\mathrm{O} / \mathrm{N}}^{\mathrm{AFC} 40}
$$

Thus the sequence from more to less negative charges should be:

$$
\left|\sigma^{\mathrm{AFC} 30}\right|>\left|\sigma^{\mathrm{AFC} 80}\right| \geq\left|\sigma^{\mathrm{AFC} 40}\right|
$$

Although, it has to be remembered that all them have an obvious amphoteric character.

A more detailed analysis has been done for the C1s, O1s and N1s peaks as shown in Figure 4. The corresponding percentages are shown in Table II.
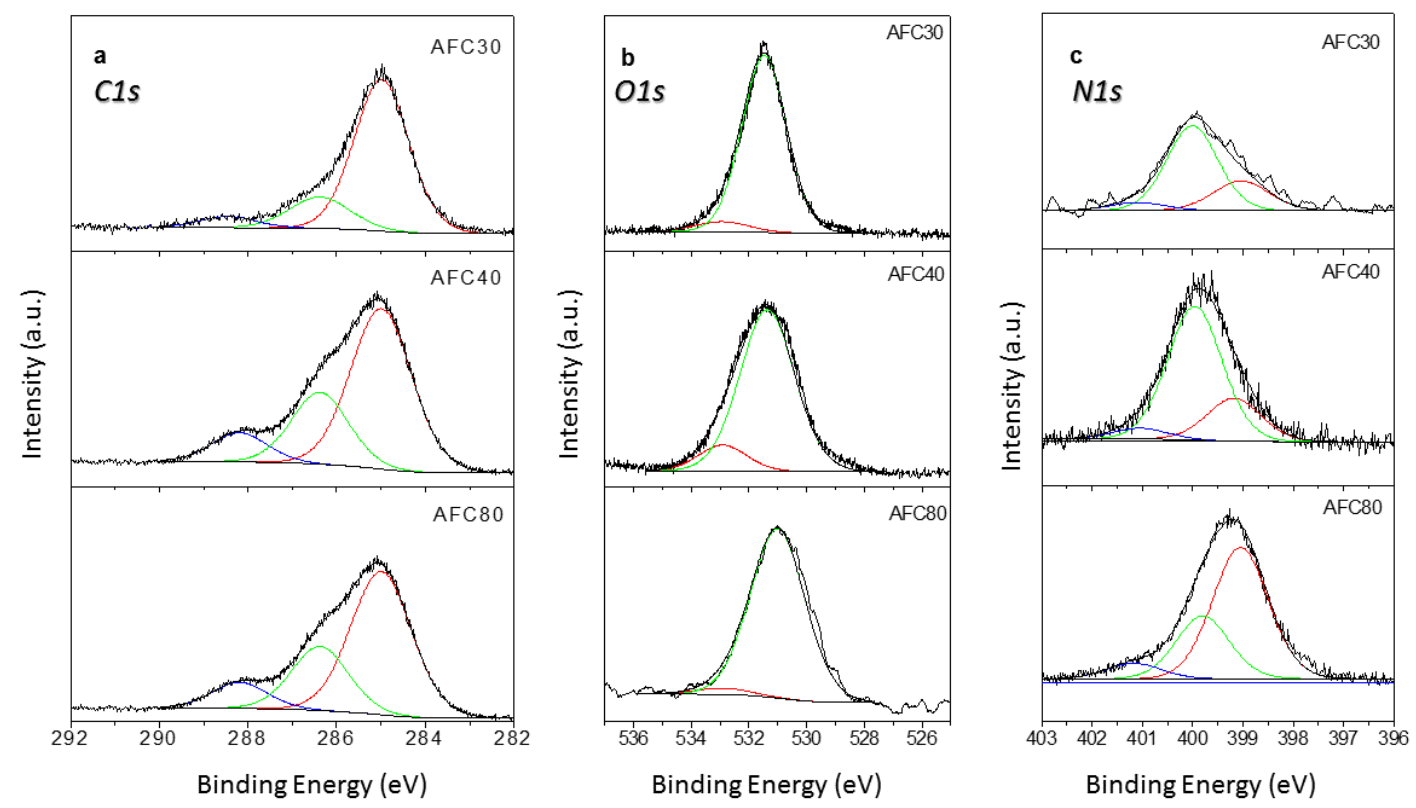

\begin{tabular}{|c|c|c|c|c|c|c|}
\hline \multirow{3}{*}{\multicolumn{2}{|c|}{ Peaks }} & \multirow{4}{*}{$\begin{array}{l}\begin{array}{l}\text { Peak } \\
\text { energy } \\
(\mathrm{eV})\end{array} \\
285\end{array}$} & \multirow{3}{*}{ Groups } & \multicolumn{3}{|c|}{ Membranes } \\
\hline & & & & AFC30 & AFC40 & AFC80 \\
\hline & & & & \multicolumn{3}{|c|}{$\begin{array}{c}\text { (\% area) ref. to the } \\
\text { element }\end{array}$} \\
\hline \multirow[t]{3}{*}{ C1s } & $\mathrm{C}_{1}$ & & $C-C, C=C$ & 76.5 & 56.6 & 63.1 \\
\hline & $\mathrm{C}_{2}$ & 286 & $C-O, C-N$ & 17.6 & 30.1 & 26.4 \\
\hline & $\mathrm{C}_{3}$ & 288 & $\begin{aligned} O & =C-O H, O=C-N, C=N, \\
C & =O\end{aligned}$ & 5.9 & 13.3 & 10.5 \\
\hline \multirow[t]{3}{*}{ N1s } & $\mathrm{N}_{1}$ & 399 & $-\mathrm{NH}_{2}$ amines & 25.7 & 22.8 & 63.4 \\
\hline & $\mathrm{N}_{2}$ & 400 & $C-N, C=N, O=C-N$ & 67.5 & 71.6 & 29.0 \\
\hline & $\mathrm{N}_{3}$ & 401 & $-\mathrm{NH}_{3}^{+},-\mathrm{NH}_{2} \mathrm{R}^{+}$ & 6.8 & 5.7 & 7.6 \\
\hline \multirow[t]{2}{*}{$\overline{\mathrm{O} 1 \mathrm{~s}}$} & $\mathrm{O}_{1}$ & 531 & $\begin{array}{l}N=C-O, O=C-N, C=O, \\
C-O\end{array}$ & 93.8 & 87.6 & 96.6 \\
\hline & $\mathrm{O}_{2}$ & 533 & $\begin{array}{l}O=C-O H, H \cdots O=C-N, \\
O=C-O\end{array}$ & 6.2 & 12.4 & 3.4 \\
\hline
\end{tabular}

Fig. 4.- Peaks fitted into C1s, O1s and N1S XPS principal peaks. 
Ang et al. [54] showed an XPS spectrum for a pure PPA (TMC-PIP) membrane they made. The corresponding percentages of the peaks fitted by them are shown in Table III.

\begin{tabular}{|c|c|c|c|c|c|c|}
\hline \multicolumn{7}{|c|}{$\begin{array}{l}\text { Table III.- XPS peaks detected for a pristine PPA membrane by Ang } \\
\text { et al. [54]. C3a and C3b correspond mainly to } N-C=O \text { and } O-C=O \\
\text { respectively. }\end{array}$} \\
\hline \multirow[t]{3}{*}{ Membrane } & \multicolumn{4}{|c|}{$\begin{array}{l}\text { C1s (\% area) } \\
\text { ref. to the element }\end{array}$} & \multicolumn{2}{|c|}{$\begin{array}{l}\text { N1s (\% area) } \\
\text { ref. to the } \\
\text { element }\end{array}$} \\
\hline & $\mathrm{C}_{1}$ & $\mathrm{C}_{2}$ & $\mathrm{C}_{3 a}$ & $\mathrm{C}_{3 b}$ & $\mathbf{N}_{1}$ & $\mathbf{N}_{2}+\mathbf{N}_{3}$ \\
\hline & $284.6 \mathrm{eV}$ & $285.6 \mathrm{eV}$ & $287.5 \mathrm{eV}$ & $288.5 \mathrm{eV}$ & $400 \mathrm{eV}$ & $401 \mathrm{eV}$ \\
\hline TMC-PIP & 47.4 & 40.8 & 9.6 & 2.2 & 11.1 & 88.9 \\
\hline
\end{tabular}

If Table II and III are compared, we can see that there is an excess of C1 and a defect of $\mathrm{C} 2$ and $\mathrm{C} 3$ in our membranes referred to the amounts contained in pure PPA. Both these effects accentuate in the sequence AFC40-AFC80-AFC30. Moreover, the relevance of the $\mathrm{N} 1$ peak increases notably in all cases and especially for the AFC80 membrane, with a clear reduction of total nitrogen (see Figure 2). The high proportion of N1 peak for all the membranes would be compatible with some modification of their surfaces to get positive charges under acidic conditions. In that connection, it is worth taking into account that AFC80 has an overwhelming proportion of amidogen or amine groups, while AFC30 and AFC40 have higher proportions of amide groups. This would contribute to make this membrane the most positively charged one at acidic $\mathrm{pH}$ as shown below in Figure 5. The presence of amidogen groups would give some more week acidic groups susceptible to give negative charges at alkaline $\mathrm{pHs}$

Pure PVA XPS spectrum corresponds to the elemental abundances displayed on Table IV [55]. According to Rogojanu et al. [56], the bond energies associated with hydroxyl functional groups of PVA $(\mathrm{C}-\mathrm{OH})$, characteristic to this polymer can be identified at $286.1 \mathrm{eV}$ and $531.0 \mathrm{eV}$, respectively in the C1s and O1s spectra. The final two C1s components at $287.6 \mathrm{eV}$ and $288.8 \mathrm{eV}$ were attributed to carboxyl and carbonyl groups resulting from incomplete alcoholysis of polyvinyl acetate to get PVA. Although some influence of the crosslinking agent could affect these figures. The corresponding peaks detectable within the $\mathrm{C}$ main peak are shown in Table $\mathrm{V}$.

\begin{tabular}{llccc}
\hline \multicolumn{6}{l}{ Table IV.- Pure PVA XPS spectrum. } & & \\
\hline Peak & \multicolumn{1}{l}{ Energy (eV) } & Percentage (global) & Percentage (elemental) \\
\hline \multirow{2}{*}{ C1s } & C1 & 285.0 & 32.4 & 49.5 \\
\cline { 2 - 5 } & C2 & 286.5 & 33.1 & 50.5 \\
\hline O1s & O2 & 532.8 & 34.5 & 100 \\
\hline
\end{tabular}

\begin{tabular}{|c|c|c|c|c|}
\hline \multicolumn{2}{|c|}{ Peak } & Energy (eV) & $\begin{array}{l}\text { Percentage } \\
\text { (elemental) }\end{array}$ & Group \\
\hline \multirow{4}{*}{ C1s } & C1 & 284.8 & 54.96 & $\mathrm{C}-\mathrm{C}, \mathrm{CH}$ \\
\hline & $\mathrm{C} 2$ & 286.1 & 38.79 & $\mathrm{C}-\mathrm{O}, \mathrm{COH}$ \\
\hline & C3a & 287.6 & 3.36 & $\mathrm{C}=\mathrm{O}$ \\
\hline & $c 3 b$ & 288.8 & 2.87 & $\mathrm{O}-\mathrm{C}=\mathrm{O}, \mathrm{COOCH}_{3}, \mathrm{COOH}$ \\
\hline
\end{tabular}


Note that PVA, according to Table V, would justify an increase of C1 and a decrease of C2 and C3 as was found for our membranes. Note also that C3 approaches the percentage that should be expected if PVA were alone on the surface of the AFC30 membrane. Of course if PVA on the surfaces of the membranes were pure, there would have not any C3 and C1 and C2 would be present in the same amounts (see Table IV). The $\mathrm{O}$ peak corroborates that PVA on the membrane surface is not pure because otherwise oxygen would give a larger $\mathrm{O} 2$ peak.

Note that attending to their nitrogen content the coverage percentages (PPA masking) of our membranes should be: $86 \%$ for AFC30, $54 \%$ for AFC80 and $50 \%$ for AFC40. Attending to their $\mathrm{O}$ or $\mathrm{C}$ contents and assuming the surface partially coated by PVA (with some content of PVAc) and taking into account that PVA and PVAc have quite similar $\mathrm{O}$ and $\mathrm{C}$ contents we can also evaluate the masking percentages arriving to quite similar results, although in these cases crosslinking could affect the figures.

One could wonder if XPS results would correspond to the active layer or could be contaminated by information corresponding to the polysulfone support. The absence of any sulfur signal in the XPS spectra analyzed assures the absence of polysulfone signals. Moreover, the maximal depth of analysis in XPS is below $10 \mathrm{~nm}$ (depending on the material) [57-59] while our active layers are around $1 \mu \mathrm{m}$ thick. A mean value of $1.3 \mu \mathrm{m}$ has been obtained for AFC80 [60] by Atomic Force Microscopy (AFM).

\subsection{Zeta potential and isoelectric point}

The zeta potential results are shown in Figure 5. From this plot the isoelectric points should be those shown in Table VI.

\begin{tabular}{lccc}
\hline Table VI.- Isoelectric points. & & & \\
\hline Membrane & AFC30 & AFC40 & AFC80 \\
\hline Isoelectric point & 3.7 & 4.1 & 4.2 \\
\hline
\end{tabular}

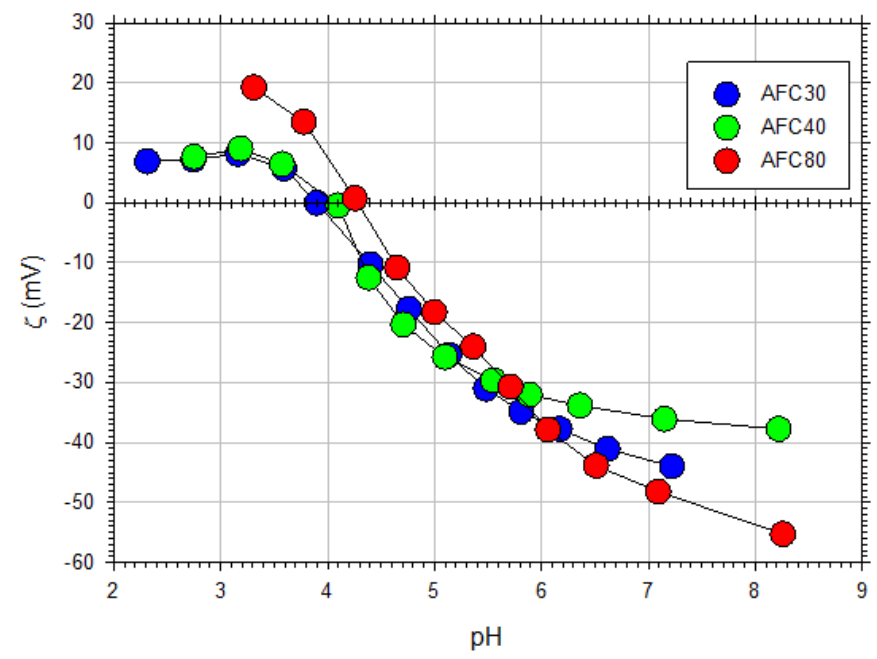

Fig. 5.- Zeta potential versus $\mathrm{pH}$ of the three membranes studied as a function of $\mathrm{pH}$.

Attending to the IPEs measured here, it seems that the order of charge densities from more to less negative ones would follow the sequence: 


$$
\left|\sigma^{\mathrm{AFC} 30}\right| \geq\left|\sigma^{\mathrm{AFC} 40}\right| \geq\left|\sigma^{\mathrm{AFC} 80}\right|
$$

Note that this order does not coincide exactly with that suggested by XPS results, $\left|\sigma^{\mathrm{AFC} 30}\right|>\left|\sigma^{\mathrm{AFC} 80}\right| \geq\left|\sigma^{\mathrm{AFC} 40}\right|$, but are completely within the range shown by Pan et al. [53]. When the sequences of $\mathrm{O} / \mathrm{N}$ and isoelectric points are compared, it is worth noting that both these parameters are quite close to each other for AFC40 and AFC80. Moreover, at $\mathrm{pH}$ below the isoelectric point AFC80 seems to be the most positively charged. At $\mathrm{pH}$ $\geq 6$ the order from more to less negative is $\left|\sigma^{\mathrm{AFC80}}\right| \geq\left|\sigma^{\mathrm{AFC30}}\right| \geq\left|\sigma^{\mathrm{AFC} 40}\right|$. This behavior would be compatible with the presence of weak basic and alkaline groups in AFC80 detected by XPS.

Isoelectric points for the AFC membranes have been scarcely measured. Gherasim et al. [9] measured the IPE of the AFC80 membrane obtaining 3.6. Szymczyk et al. [61] obtained an isoelectric point close to 5 for the AFC30 membrane. Others relay on these estimations too [8, 10]. Qadir et al. [62] accept also these results while underlying the similarities of the actual IPEs for these membranes and their susceptibility to ionic adsorption.

\subsection{AFM and pore sizes}

Examples of AFM pictures of the membranes studied here are shown in 3D in Figure 6.

Fig. 6.- 3D AFM images of the three membranes studied here.

The pore size distributions obtained from AFM image analysis are displayed in Figure 7 along with the corresponding log-normal fitted distributions and corresponding pore radii. AFC40 and AFC80 pore size distributions were previously shown elsewhere by us [22]. Frequencies are normalized to unit area.

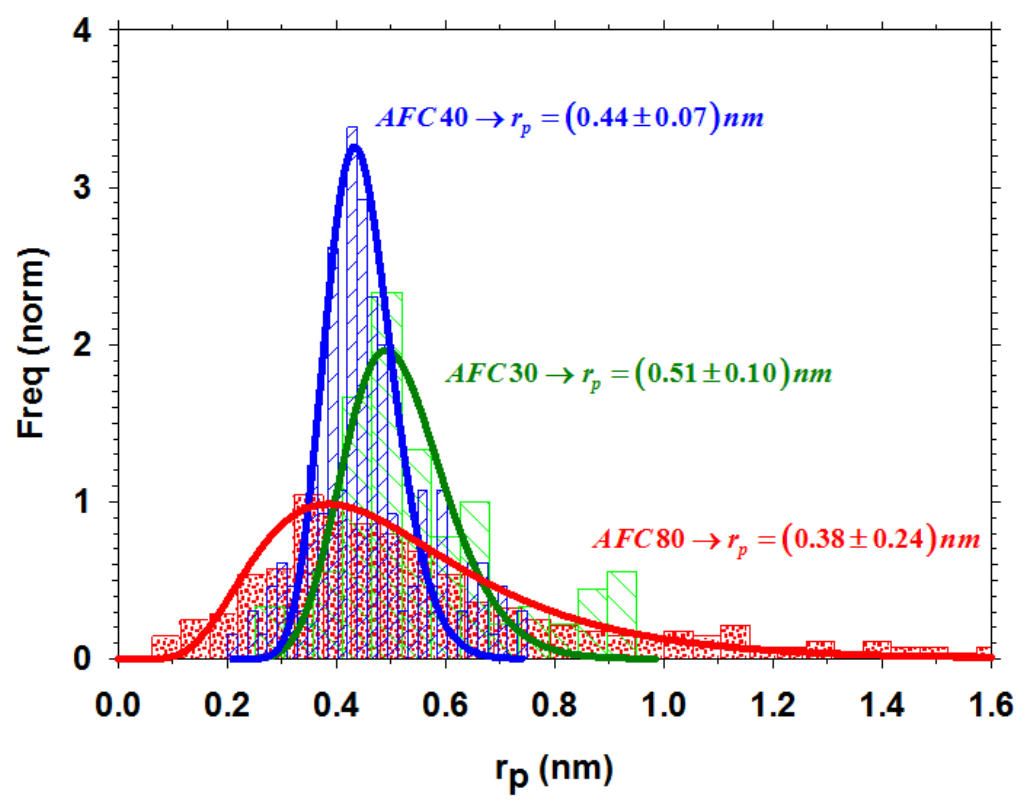

Fig. 7.- Pore size distribution of the three membranes studied obtained from Image analysis of AFM pictures. 
AFM image analysis tends to take as pore entrances some apparent pore entrances (actually deep valleys) somehow distorting the actual pore radii distributions. Our membranes follow the sequence (from wider to narrower mean pore sizes, $\left\langle r_{p}\right\rangle$ ):

$$
\left\langle\mathrm{r}_{\mathrm{p}}^{\mathrm{AFC} 30}\right\rangle \geq\left\langle\mathrm{r}_{\mathrm{p}}^{\mathrm{AFC} 40}\right\rangle \geq\left\langle\mathrm{r}_{\mathrm{p}}^{\mathrm{AFC} 80}\right\rangle
$$

It is worth noting that pore size distributions are wide enough as to permit very similar retentions for uncharged molecules. For example galactose (molecular radius of $0.42 \mathrm{~nm}$ [63] give very similar true retention for both AFC40 and AFC80 being even slightly higher for AFC40 [22].

Fractal dimensions, roughness and the Wenzel index are shown in Table VII. It can be seen that fractal dimensions are quite similar but increase as mean pore sizes do. Note that all fractal dimensions are between 2 and 3 meaning that the surface of our membranes defines a fuzzy interface that has characteristics in between 2D and 3D spaces. Roughness decreases as pore sizes increase. It is quite similar for AFC80 and AFC40 and substantially decreases for AFC30. The inverse tendency of roughness and fractal dimension, shown in Table VII, would correspond to increasing heights (high roughness) widely separated from each other (low fractal dimension) or, oppositely to highly fractured surfaces (high fractal dimension) with small heights (low roughness). The Wenzel index follows the same trend than roughness.

\begin{tabular}{lccc}
\hline $\begin{array}{l}\text { Table VII.- Fractal dimension and roughness } \\
\text { regions). }\end{array}$ & AFC80 & AFC40 & AFC30 \\
\hline Membrane & 2.06 & 2.11 & 2.22 \\
\hline Fractal dimension $\mathrm{D}_{\mathrm{f}}$ & 14.42 & 10.48 & 1.79 \\
\hline Roughness $\mathrm{R}_{\mathrm{a}}(\mathrm{nm})$ & 19.40 & 13.85 & 2.47 \\
\hline Roughness $\mathrm{R}_{\mathrm{q}}(\mathrm{nm})$ & 1.30 & 1.22 & 1.08 \\
\hline Wenzel index $\mathrm{rw}$ & & &
\end{tabular}

Do et al. [64, 65] showed that roughness decreases usually for increasingly coated membranes. An et al. [44] proved that roughness decreased also when PVA was copolymerized with TMC-PIP. In our case, roughness increases as nitrogen decreases, which is compatible with both coating and copolymerization. In some cases, areas of heterogeneous roughness have been correlated by us with different XPS elemental abundances revealing incomplete surface coating, [66]. Here, any relevant heterogeneity has been detected. Misdan et al. measured roughness of TFC poly(piperazine-amide) membranes on different substrates obtaining: PSf-based $(21.0 \mathrm{~nm})>$ PEI-based $(14.4$ $\mathrm{nm})>$ PES-based $(12.6 \mathrm{~nm})$ [46], which are within the range obtained here for AFC40 and AFC80.

\subsection{Contact Angles}

Contact angles increase (and wettability decreases), as shown in Table VIII, according to the sequence:

$$
\theta^{\mathrm{AFC} 30}<\theta^{\mathrm{AFC} 80} \leq \theta^{\mathrm{AFC} 40}
$$

Table VIII.- Apparent and material contact angles. 


\begin{tabular}{llll}
\hline $\begin{array}{l}\text { Apparent contact angle } \\
\theta_{\text {app }}(\text { deg })\end{array}$ & 31.0 & 59.9 & 56.6 \\
\hline $\begin{array}{l}\text { Material contact angle } \\
\theta(\text { deg })\end{array}$ & 37.5 & 65.7 & 64.9 \\
\hline
\end{tabular}

Adeniyi and coworkers give wide ranges for the apparent contact angles for AFC $40\left(30^{\circ}-40^{\circ}\right)$ and AFC 80 membranes $\left(32^{\circ}-50^{\circ}\right)$ [67]. Dudziak [68] obtained an apparent contact angle of $31^{\circ}$ for the AFC 30 membrane. It is worth taking into account that according to Misdan et al [47] a pure pyperazine membrane over a polysulfone substrate gives a contact angle of $54^{\circ}$.

Tezuka et al. measured the contact angle for pure PVA films and obtained a value of $51^{\circ}$ [69] which are near those obtained by us for AFC80 or AFC40 membranes. Dražević et al. showed that addition of PVA on an NF270 membrane increases contact angle when low crosslinking was attained [70].

\subsection{Permeation and Retention}

Pure water permeabilities, $\mathrm{L}_{\mathrm{w}}$, are shown in Table IX. Porosities as predicted by the Hagen-Poiseuille equation for an active layer thickness of $1 \mu \mathrm{m}$, are also shown. It is worth noting that these porosities could be affected by their quite different contact angles (see table VIII). Permeabilities decrease as:

$$
\mathrm{L}_{\mathrm{W}}^{\mathrm{AFC} 30}>\mathrm{L}_{\mathrm{W}}^{\mathrm{AFC} 40}>\mathrm{L}_{\mathrm{W}}^{\mathrm{AFC80}}
$$

This is also the order of the calculated porosities. Note that porosity of AFC80 agrees with that evaluated previously by us by several different methods [60].

\begin{tabular}{lccc}
\hline $\begin{array}{l}\text { Table IX.- Pure water permeability } \mathrm{L}_{\mathrm{w}} \text { and } \\
\text { porosity } \Theta \text {. }\end{array}$ \\
\hline Membrane & AFC30 & AFC40 & AFC80 \\
\hline $\begin{array}{c}\text { Permeability } \\
\mathrm{L}_{\mathrm{w}}\left(\mathbf{1 0 ^ { - 1 1 }} \mathbf{~ m} / \mathbf{s} \cdot \mathrm{Pa}\right)\end{array}$ & 1.37 & 1.09 & 0.43 \\
\hline $\begin{array}{c}\text { Porosity } \\
\Theta(\%)\end{array}$ & 35.0 & 27.9 & 11.0 \\
\hline
\end{tabular}

Figures 8 and 9 show the observed and true retention coefficients for the three membranes and three solutes studied. Here $\alpha=0.8$, according to the Chilton-Colburn correlation, has been used because it leaded to more consistent results. Actually, this election for $\alpha$ has been proved to give good results by us [12, 13, 22, 60] for some of our membranes. Note that true and observed retention coefficients are quite similar, what means that fluid mechanics of the NF plant is quite efficient in avoiding significant contributions of concentration-polarization. Although as can be seen true retention is always over the observed one. Note that some true retention coefficients are not plotted as far as the variable speed method did not give consistent results for $\mathrm{R}_{\mathrm{t}}$ in those cases. 

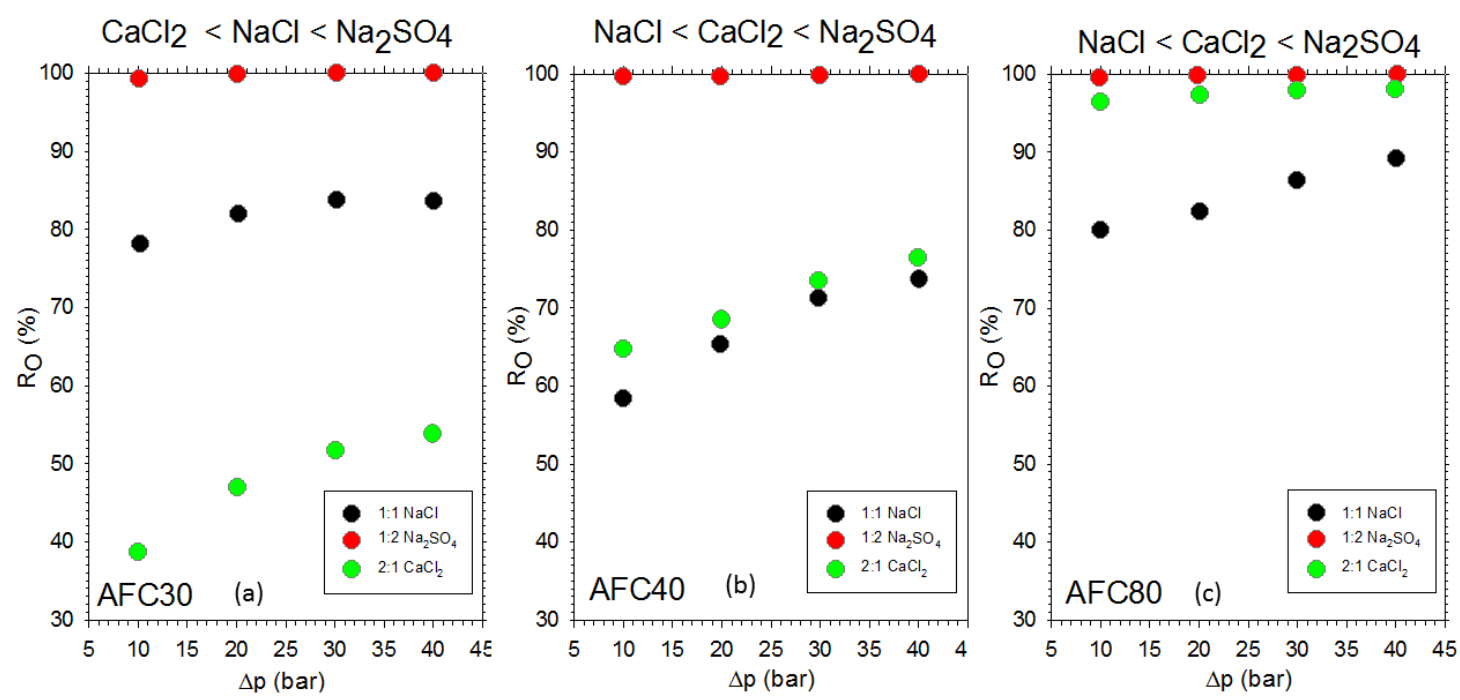

Fig. 8.- Observed retention of the different ions through the three membranes studied.
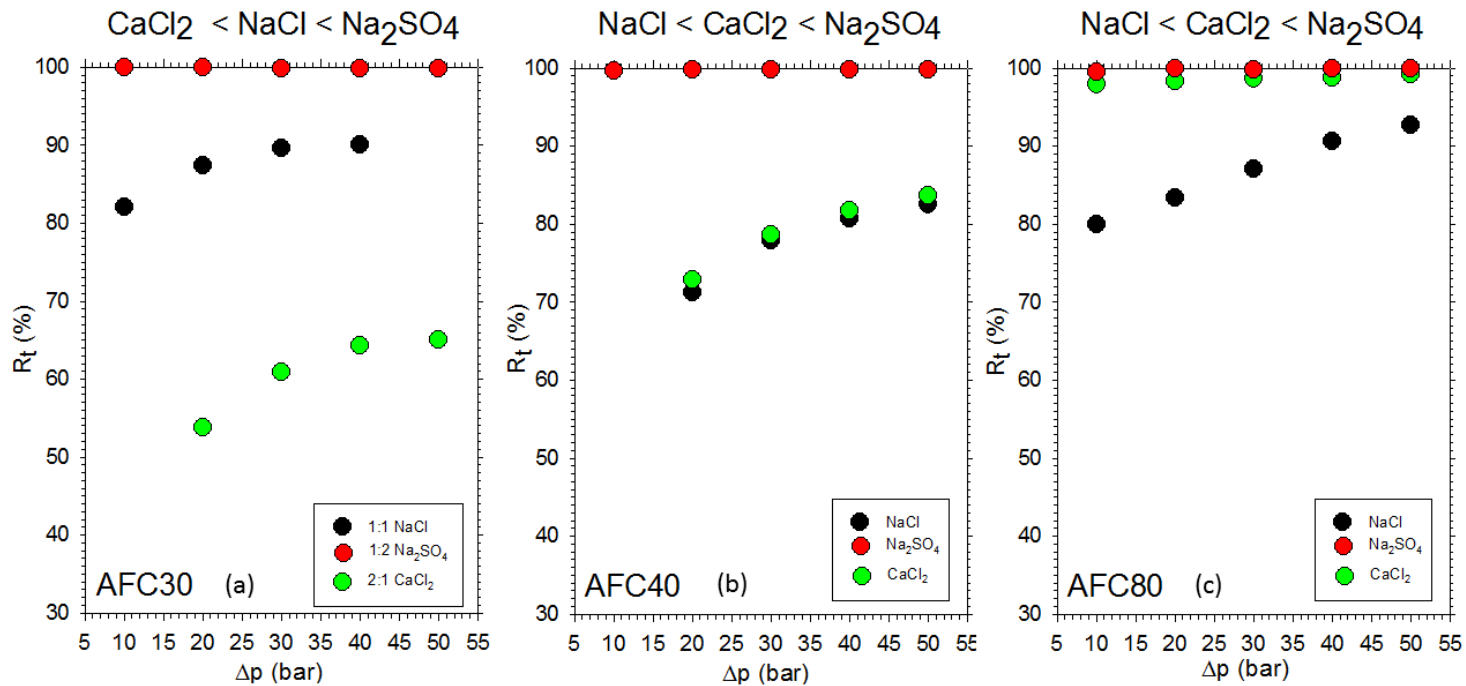

Fig. 9.- True retention of the different ions through the three membranes studied.

If there were PVA within the bulk material of our membranes [44] retention would decrease with PVA content what does not. Rather, retention does follow pore size order as seems reasonable. Note as well that $\mathrm{NaCl}$ retention is in accordance with data given by the supplier.

The salt retentions for each membrane gives insights on the electrostatic contributions to retention. Retention coefficients for different salts seem [71] to be determined by: 1) Donnan exclusion or 2) diffusion coefficients. Pure diffusion factors would give retention coefficients $\mathrm{R}\left(\mathrm{Na}_{2} \mathrm{SO}_{4}\right)>\mathrm{R}\left(\mathrm{CaCl}_{2}\right)>\mathrm{R}(\mathrm{NaCl})$. Among those determined by electrostatic interaction (Donnan exclusion) they can show the sequence $\mathrm{R}\left(\mathrm{Na}_{2} \mathrm{SO}_{4}\right)>\mathrm{R}(\mathrm{NaCl})>\mathrm{R}\left(\mathrm{CaCl}_{2}\right)$ as for negatively charged membranes or the sequence $\mathrm{R}\left(\mathrm{CaCl}_{2}\right)>\mathrm{R}(\mathrm{NaCl})>\mathrm{R}\left(\mathrm{Na}_{2} \mathrm{SO}_{4}\right)$ for positively charged membranes. 
After the examination of Figure 8, it seems clear that membrane AFC 40 acts as substantially neutral with diffusion determined salt retention. AFC80 gives salt retentions that correlate with diffusive factors but strongly affected by its amphoteric character as shown by its quite similar retentions for the $\mathrm{R}\left(\mathrm{CaCl}_{2}\right) \sqcup \mathrm{R}\left(\mathrm{Na}_{2} \mathrm{SO}_{4}\right)$. It is worth noting that diffusion might be important for AFC 80 attending to its narrow mean pore size but this membrane shows as well an intense amphoteric character being strongly positive below the isoelectric point (acidic range) and equally strongly negative over it (alkaline range) as shown in Figure 5. Finally, AFC 30 seems to be clearly negatively charged.

The electrical character according to the Peeters' series would mean that charges are from more to less negative, in the order:

$$
\left|\sigma^{\mathrm{AFC} 30}\right|>\left|\sigma^{\mathrm{AFC} 80}\right| \geq\left|\sigma^{\mathrm{AFC} 40}\right|
$$

This sequence coincides with that of $\mathrm{O} / \mathrm{N}$ ratios rather than with that of the isoelectric points, $\left|\sigma^{\mathrm{AFC} 30}\right| \geq\left|\sigma^{\mathrm{AFC} 40}\right| \geq\left|\sigma^{\mathrm{AFC} 80}\right|$. This Peeters' trend for charges would agree with the tendency of wettability to increase for more charged (polar) surfaces.

\section{Conclusions}

A series of TFC membranes, three AFC membranes from PCI, have been characterized by using XPS, AFM, contact angles, zeta potential and salt permeation experiments. All these methods are complimentary to get an accurate image of the main characteristics of these membranes. They actually coincide in showing a certain order among the membranes giving an insight in how they are manufactured. These trends are summarized in Table X.

Table X.- Summary of surface characteristics of the AFC membranes studied here.

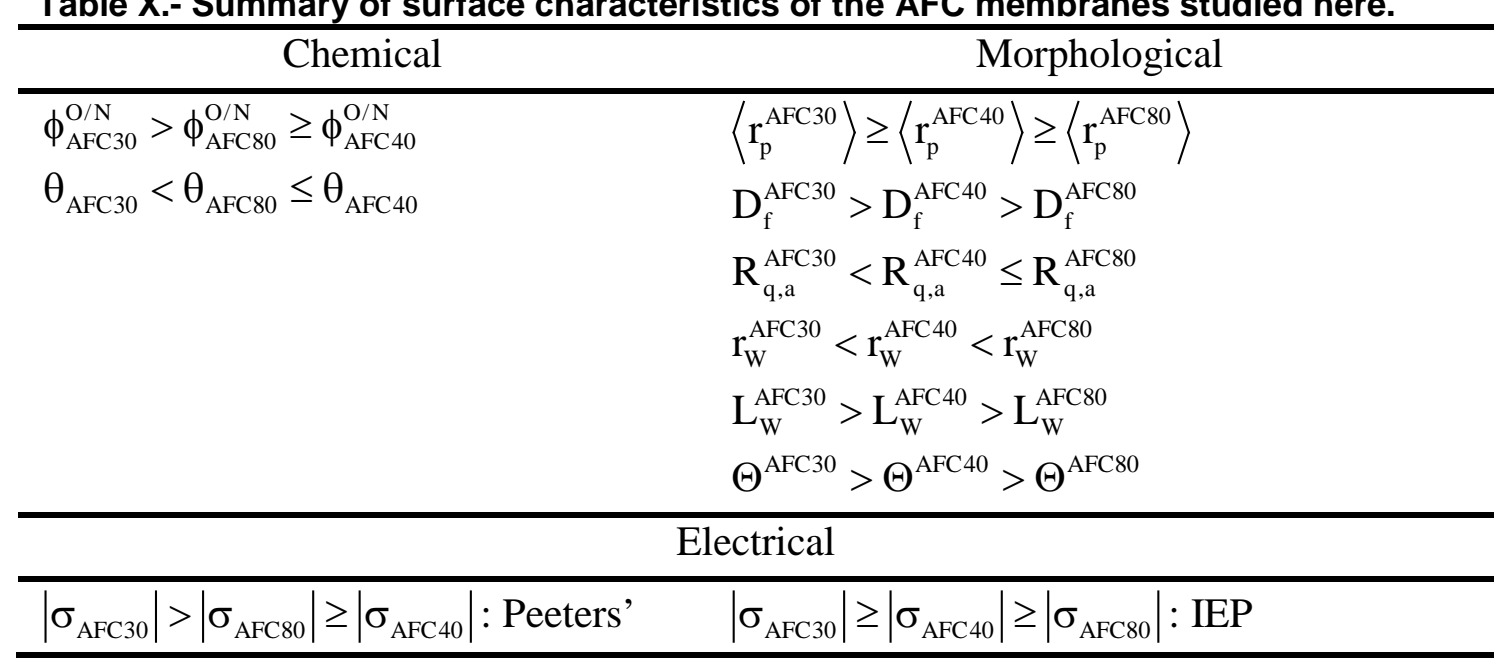

AFC30 gives the highest mean pore radius, although quite similar to those of AFC40 and AFC 80 that has the smallest pore size. Water permeability shows a quite similar trend to that of pore radii with the highest permeability corresponding to AFC30. 
Porosity decreases with increasing pore radii. Roughness and Wenzel index are quite small for AFC30 and increase as pore radii decrease while fractal dimension decreases.

AFC30 membrane has the smallest nitrogen content what should be compatible with a highest coverage of PVA. AFC40 has the highest nitrogen content, although it is quite similar to that of AFC80. Contact angles follow the same sequence, increasing when the amount of nitrogen increases. Equivalently, hydrophilicity increases with PVA coverage until being maximal for the AFC30 membrane.

Finally, charges are similar although their isoelectric points are clearly more acidic for AFC30 and less acidic for AFC40 and AFC80. Thus the isoelectric point seems to be more acidic for increasing pore sizes. Nevertheless, according to salt-retention, and the Peeter's procedure, charge should be more negative with increasing amounts of oxygen on the membrane surface (increasing coverage on the PPA active layer) rather than being correlated with pore radii. The high content of PVA on the AFC30 membrane would contribute to give low retentions for $\mathrm{CaCl}_{2}$ due to some shielding of the charged groups. AFC40 and AFC 80, with very similar PVA coverage can be differentiated by the presence of weak acid and basic groups on AFC80, not totally covered by the PVA coating, that give a quite similar (and high) retention of $\mathrm{CaCl}_{2}$ and $\mathrm{Na}_{2} \mathrm{SO}_{4}$.

In summary, the studied membranes are quite similar in size and charge. Morphological properties (porosity, water permeability, fractal dimension, Wenzel parameter and roughness) show monotonous tendencies with pore size. While functional characteristics (wettability, charge and salt retention) appear as ordered according to the $\mathrm{O} / \mathrm{N}$ ratio (PVA coverage).

\section{Acknowledgements}

Authors thank the Spanish Ministerio de Educación y Ciencia (Plan Nacional de I+D+i) through project MAT2016-76413-C2-1-R and Junta de Castilla y León (project VA088G19).

\section{Data availability}

Neither raw nor processed data, other than those already included here, that could help to reproduce these findings, can be shared at this time due to technical or time limitations. Data included through tables and/or graphs are mostly unprocessed and they would be sufficient to reproduce the results shown here.

\section{References}

[1] A.W. Mohammad, Y.H. Teow, W.L. Ang, Y.T. Chung, D.L. Oatley-Radcliffe, N. Hilal, Nanofiltration membranes review: Recent advances and future prospects, Desalination 356 (2015) 226-254.

[2] S.S. Hosseini, E. Bringas, N.R. Tan, I. Ortiz, M. Ghahramani, M.A. Alaei Shahmirzadi, Recent progress in development of high performance polymeric membranes and materials for metal plating wastewater treatment: A review, Journal of Water Process Engineering 9 (2016) 78-110. 
[3] S. Tul Muntha, A. Kausar, M. Siddiq, Advances in Polymeric Nanofiltration Membrane: A Review, Polymer-Plastics Technology and Engineering 56(8) (2017) 841856.

[4] M. Paul, S.D. Jons, Chemistry and fabrication of polymeric nanofiltration membranes: A review, Polymer 103 (2016) 417-456.

[5] M.P. W., Condensation Polymers: By Interfacial and Solution Methods., John Wiley \& Sons, Ltd, New York London-Sydney, 1966.

[6] W.J. Lau, A.F. Ismail, N. Misdan, M.A. Kassim, A recent progress in thin film composite membrane: A review, Desalination 287 (2012) 190-199.

[7] W.J. Lau, S. Gray, T. Matsuura, D. Emadzadeh, J. Paul Chen, A.F. Ismail, A review on polyamide thin film nanocomposite (TFN) membranes: History, applications, challenges and approaches, Water Research 80 (2015) 306-324.

[8] S. Bouranene, P. Fievet, A. Szymczyk, M. El-Hadi Samar, A. Vidonne, Influence of operating conditions on the rejection of cobalt and lead ions in aqueous solutions by a nanofiltration polyamide membrane, Journal of Membrane Science 325(1) (2008) 150157.

[9] C.-V. Gherasim, J. Cuhorka, P. Mikulášek, Analysis of lead(II) retention from single salt and binary aqueous solutions by a polyamide nanofiltration membrane: Experimental results and modelling, Journal of Membrane Science 436 (2013) 132-144.

[10] P. Mikulášek, J. Cuhorka, Removal of Heavy Metal Ions from Aqueous Solutions by Nanofiltration, Chemical Engineering Transactions 47 (2016) 379-384.

[11] K. V., C. J., D. L., M. P., Application of nanofiltration for removal of zinc from industrial wastewater, Desalination and Water Treatment 75 (2017) 342-347.

[12] A. Otero-Fernandez, J.A. Otero, A. Maroto, J. Carmona, L. Palacio, P. Pradanos, A. Hernandez, Concentration-polarization in nanofiltration of low concentration $\mathrm{Cr}(\mathrm{VI})$ aqueous solutions. Effect of operative conditions on retention, Journal of Cleaner Production 150 (2017) 243-252.

[13] A. Otero-Fernandez, J.A. Otero, A. Maroto-Valiente, J.I. Calvo, L. Palacio, P. Pradanos, A. Hernandez, Reduction of $\mathrm{Pb}(\mathrm{II})$ in water to safe levels by a small tubular membrane nanofiltration plant, Clean Technologies and Environmental Policy 20(2) (2018) 329-343.

[14] M. C.P., T. C., Experimental Assesment of Nanofiltration for the Removal of Chlorophenols from Aqueous Effluents, Environmental Engineering and Management Journal 16(4) (2017) 793-800.

[15] Q. D., M. H., K. L.K., Retention of sulfate and chloride ions in commercially available tubular membranes, Membrane Water Treatment 8(4) (2017) 369-380.

[16] K. Walha, R.B. Amar, P. Bourseau, P. Jaouen, Nanofiltration of concentrated and salted tuna cooking juices, Process Safety and Environmental Protection 87(5) (2009) 331-335.

[17] N. Pap, S. Kertész, E. Pongrácz, L. Myllykoski, R.L. Keiski, G. Vatai, Z. László, S. Beszédes, C. Hodúr, Concentration of blackcurrant juice by reverse osmosis, Desalination 241(1) (2009) 256-264.

[18] D. Qadir, H. Mukhtar, L.K. Keong, Retention of sulfate and chloride ions in commercially available tubular membranes, Membrane Water Treatment 8(4) (2017) 369-380.

[19] B. D., Surface analysis of polymers by XPS and static SIMS, Cambridge University Press, Cambridge, 1998.

[20] B. G., B. D., High resolution XPS of Organic Polymers, The Scienta ESCA 300 database, John Wiley and Sons, Chichester, UK, 1992. 
[21] M. Vilaseca, E. Mateo, L. Palacio, P. Prádanos, A. Hernández, A. Paniagua, J.n. Coronas, J. Santamaría, AFM characterization of the growth of MFI-type zeolite films on alumina substrates, Microporous and Mesoporous Materials 71(1) (2004) 33-37.

[22] J.A. Otero, O. Mazarrasa, J. Villasante, V. Silva, P. Prádanos, J.I. Calvo, A. Hernández, Three independent ways to obtain information on pore size distributions of nanofiltration membranes, Journal of Membrane Science 309(1) (2008) 17-27.

[23] A.L. Carvalho, F. Maugeri, V. Silva, A. Hernández, L. Palacio, P. Pradanos, AFM analysis of the surface of nanoporous membranes: application to the nanofiltration of potassium clavulanate, Journal of Materials Science 46(10) (2011) 3356-3369.

[24] L. Fernández, M. Sánchez, F.J. Carmona, L. Palacio, J.I. Calvo, A. Hernández, P. Prádanos, Analysis of the Grafting Process of PVP on a Silicon Surface by AFM and Contact Angle, Langmuir 27(18) (2011) 11636-11649.

[25] G. Wolansky, A. Marmur, Apparent contact angles on rough surfaces: the Wenzel equation revisited, Colloids and Surfaces A: Physicochemical and Engineering Aspects 156(1) (1999) 381-388.

[26] O. J.A., L. G., C. J.M., M. O., Planta piloto universal móvil de ensayo de membranas mediante gradiente de presión para Microfiltración (MF), Ultrafiltración (UF), Nanofiltración (NF) y Ósmosis Inversa (OI/RO), Spain, 2008.

[27] Handbook of Chemistry and Physics, CRC-Press, Boca Raton, Florida, USA, 1983. [28] V. Gekas, B. Hallström, Mass transfer in the membrane concentration polarization layer under turbulent cross flow: I. Critical literature review and adaptation of existing sherwood correlations to membrane operations, Journal of Membrane Science 30(2) (1987) 153-170.

[29] G.B. van den Berg, I.G. Rácz, C.A. Smolders, Mass transfer coefficients in crossflow ultrafiltration, Journal of Membrane Science 47(1) (1989) 25-51.

[30] P. Prádanos, J.I. Arribas, A. Hernández, Mass transfer coefficient and retention of PEGs in low pressure cross-flow ultrafiltration through asymmetric membranes, Journal of Membrane Science 99(1) (1995) 1-20.

[31] E. Nagy, Chapter 1 - Membrane Materials, Characterization, and Transport Properties, in: E. Nagy (Ed.), Basic Equations of Mass Transport Through a Membrane Layer (Second Edition), Elsevier2019, pp. 1-10.

[32] C.Y. Tang, Y.-N. Kwon, J.O. Leckie, Effect of membrane chemistry and coating layer on physiochemical properties of thin film composite polyamide RO and NF membranes: I. FTIR and XPS characterization of polyamide and coating layer chemistry, Desalination 242(1) (2009) 149-167.

[33] C.Y. Tang, Y.-N. Kwon, J.O. Leckie, Probing the nano- and micro-scales of reverse osmosis membranes-A comprehensive characterization of physiochemical properties of uncoated and coated membranes by XPS, TEM, ATR-FTIR, and streaming potential measurements, Journal of Membrane Science 287(1) (2007) 146-156.

[34] C.Y. Tang, Y.-N. Kwon, J.O. Leckie, Effect of membrane chemistry and coating layer on physiochemical properties of thin film composite polyamide RO and NF membranes: II. Membrane physiochemical properties and their dependence on polyamide and coating layers, Desalination 242(1) (2009) 168-182.

[35] N. Combernoux, L. Schrive, V. Labed, Y. Wyart, E. Carretier, A. Benony-Rhodier, P. Moulin, Study of polyamide composite reverse osmosis membrane degradation in water under gamma rays, Journal of Membrane Science 480 (2015) 64-73.

[36] N. Combernoux, L. Schrive, V. Labed, Y. Wyart, E. Carretier, P. Moulin, Irradiation effects on RO membranes: Comparison of aerobic and anaerobic conditions, Polymer Degradation and Stability 134 (2016) 126-135. 
[37] S. Inukai, R. Cruz-Silva, J. Ortiz-Medina, A. Morelos-Gomez, K. Takeuchi, T. Hayashi, A. Tanioka, T. Araki, S. Tejima, T. Noguchi, M. Terrones, M. Endo, Highperformance multi-functional reverse osmosis membranes obtained by carbon nanotube·polyamide nanocomposite, Scientific Reports 5 (2015) 13562.

[38] X. Wei, Z. Wang, Z. Zhang, J. Wang, S. Wang, Surface modification of commercial aromatic polyamide reverse osmosis membranes by graft polymerization of 3-allyl-5,5dimethylhydantoin, Journal of Membrane Science 351(1) (2010) 222-233.

[39] L. Li, S. Zhang, X. Zhang, Preparation and characterization of poly(piperazineamide) composite nanofiltration membrane by interfacial polymerization of 3,3',5,5'-biphenyl tetraacyl chloride and piperazine, Journal of Membrane Science 335(1) (2009) 133-139.

[40] R. Mehta, H. Brahmbhatt, M. Mukherjee, A. Bhattacharya, Tuning separation behavior of tailor-made thin film poly(piperazine-amide) composite membranes for pesticides and salts from water, Desalination 404 (2017) 280-290.

[41] P. Wen, Y. Chen, X. Hu, B. Cheng, D. Liu, Y. Zhang, S. Nair, Polyamide thin film composite nanofiltration membrane modified with acyl chlorided graphene oxide, Journal of Membrane Science 535 (2017) 208-220.

[42] R.J. Petersen, Composite reverse osmosis and nanofiltration membranes, Journal of Membrane Science 83(1) (1993) 81-150.

[43] F. Yang, S. Zhang, D. Yang, X. Jian, Preparation and characterization of polypiperazine amide/PPESK hollow fiber composite nanofiltration membrane, Journal of Membrane Science 301(1) (2007) 85-92.

[44] Q. An, F. Li, Y. Ji, H. Chen, Influence of polyvinyl alcohol on the surface morphology, separation and anti-fouling performance of the composite polyamide nanofiltration membranes, Journal of Membrane Science 367(1) (2011) 158-165.

[45] B.-M. Jun, H.K. Lee, Y.-N. Kwon, Acid-catalyzed hydrolysis of semi-aromatic polyamide NF membrane and its application to water softening and antibiotics enrichment, Chemical Engineering Journal 332 (2018) 419-430.

[46] N. Misdan, W.J. Lau, A.F. Ismail, T. Matsuura, D. Rana, Study on the thin film composite poly(piperazine-amide) nanofiltration membrane: Impacts of physicochemical properties of substrate on interfacial polymerization formation, Desalination 344 (2014) 198-205.

[47] N. Misdan, W.J. Lau, C.S. Ong, A.F. Ismail, T. Matsuura, Study on the thin film composite poly(piperazine-amide) nanofiltration membranes made of different polymeric substrates: Effect of operating conditions, Korean Journal of Chemical Engineering 32(4) (2015) 753-760.

[48] A.E. Childress, M. Elimelech, Relating Nanofiltration Membrane Performance to Membrane Charge (Electrokinetic) Characteristics, Environmental Science \& Technology 34(17) (2000) 3710-3716.

[49] M. Wiśniewska, K. Szewczuk-Karpisz, I. Ostolska, T. Urban, K. Terpiłowski, V.I. Zarko, V.M. Gun'ko, Effect of polyvinyl alcohol adsorption on the mixed aluminasilica-titania suspension stability, Journal of Industrial and Engineering Chemistry 23 (2015) 265-272.

[50] A. Rogojanu, E. Rusu, N. Olaru, M. Dobromir, D.O. Dorohoi, Development and characterization of poly(vinyl alcohol) matrix for drug release, Digest Journal of Nanomaterials and Biostructures 6(2) (2018) 809-818.

[51] F. Peng, X. Huang, A. Jawor, E.M.V. Hoek, Transport, structural, and interfacial properties of poly(vinyl alcohol)-polysulfone composite nanofiltration membranes, Journal of Membrane Science 353(1) (2010) 169-176. 
[52] M. Wiśniewska, V. Bogatyrov, I. Ostolska, K. Szewczuk-Karpisz, K. Terpiłowski, A. Nosal-Wiercińska, Impact of poly(vinyl alcohol) adsorption on the surface characteristics of mixed oxide MnxOy-SiO2, Adsorption 22(4) (2016) 417-423.

[53] Y. Pan, R. Xu, Z. Lü, S. Yu, M. Liu, C. Gao, Enhanced both perm-selectivity and fouling resistance of poly(piperazine-amide) nanofiltration membrane by incorporating sericin as a co-reactant of aqueous phase, Journal of Membrane Science 523 (2017) 282290.

[54] M.B.M.Y. Ang, Y.-L. Ji, S.-H. Huang, H.-A. Tsai, W.-S. Hung, C.-C. Hu, K.-R. Lee, J.-Y. Lai, Incorporation of carboxylic monoamines into thin-film composite polyamide membranes to enhance nanofiltration performance, Journal of Membrane Science 539 (2017) 52-64.

[55] P. Louette, F. Bodino, J.-J. Pireaux, Poly(vinyl alcohol) (PVA) XPS Reference Core Level and Energy Loss Spectra, Surface Science Spectra 12(1) (2005) 106-110.

[56] R. A., R. E., O. N., D. M., D.D. O., Development and characterization of poly(vinyl alcohol) matrix for drug release, Digest Journal of Nanomaterials and Biostructures 6(2) (2018) 809-818.

[57] C.J. Powell, A. Jablonski, Surface Sensitivity of Auger-Electron Spectroscopy and X-ray Photoelectron Spectroscopy, Journal of Surface Analysis 17(3) (2011) 170-176.

[58] O.M. J.J., T. H.R., Surface Studies on Multicomponent Polymeric Solids, in: M.C. Shen (Ed.), Contemporary Topics in Polymer Science, Plenum Press, New York, USA, 1979, pp. 215-228.

[59] P. D., S. F., X-Ray Photoelectron Spectroscopy, in: M. Stamm (Ed.), Polymer Surfaces and Interfaces Characterization, Modification and Applications, Springer, Berlin, Germany, 2008, pp. 71-89.

[60] J.A. Otero, G. Lena, J.M. Colina, P. Prádanos, F. Tejerina, A. Hernández, Characterisation of nanofiltration membranes: Structural analysis by the DSP model and microscopical techiques, Journal of Membrane Science 279(1) (2006) 410-417.

[61] A. Szymczyk, N. Fatin-Rouge, P. Fievet, Tangential streaming potential as a tool in modeling of ion transport through nanoporous membranes, Journal of Colloid and Interface Science 309(2) (2007) 245-252.

[62] D. Qadir, H.B. Mukhtar, L.K. Keong, Rejection of divalent ions in commercial tubular membranes: Effect of feed concentration and anion type, Sustainable Environment Research 27(2) (2017) 103-106.

[63] S.G. Schultz, A.K. Solomon, Determination of the Effective Hydrodynamic Radii of Small Molecules by Viscometry, The Journal of General Physiology 44(6) (1961) 1189.

[64] V.T. Do, C.Y. Tang, M. Reinhard, J.O. Leckie, Degradation of Polyamide Nanofiltration and Reverse Osmosis Membranes by Hypochlorite, Environmental Science \& Technology 46(2) (2012) 852-859.

[65] J.S. Louie, I. Pinnau, I. Ciobanu, K.P. Ishida, A. Ng, M. Reinhard, Effects of polyether-polyamide block copolymer coating on performance and fouling of reverse osmosis membranes, Journal of Membrane Science 280(1) (2006) 762-770.

[66] L. Palacio, P. Pradanos, A. Hernandez, M.J. Ariza, J. Benavente, M. Nystrom, Phasecontrast scanning force microscopy and chemical heterogeneity of GR polysulfone ultrafiltration membranes, Applied Physics a-Materials Science \& Processing 73(5) (2001) 555-560.

[67] A. Adeniyi, R. Mbaya, M. Onyango, P. Popoola, T. Brooms, Membrane selection for organic contaminats removal from Hastbeespoort Dam Water in South Africa, WIT Transactions on Ecology and the Environment 223 (2017) 583-592. 
[68] D. M., Retention of mycoestrogens in nanofiltration. Impact of feed water chemistry, membrane properties and operating process conditions, Environment Protection Engineering 38(2) (2012) 5-17.

[69] Y. Tezuka, A. Fukushima, S. Matsui, K. Imai, Surface studies on poly(vinyl alcohol)—poly(dimethylsiloxane) graft copolymers, Journal of Colloid and Interface Science 114(1) (1986) 16-25.

[70] E. Dražević, K. Košutić, V. Dananić, D.M. Pavlović, Coating layer effect on performance of thin film nanofiltration membrane in removal of organic solutes, Separation and Purification Technology 118 (2013) 530-539.

[71] J.M.M. Peeters, J.P. Boom, M.H.V. Mulder, H. Strathmann, Retention measurements of nanofiltration membranes with electrolyte solutions, Journal of Membrane Science 145(2) (1998) 199-209. 


\section{Table Titles}

Table I.- XPS elemental percentages. (ref. to the global amount).

Table II.- Analyzed XPS peaks and their corresponding groups.

Table III.- XPS peaks detected for a pristine PPA membrane by Ang et al. C3a and C3b correspond mainly to $\mathrm{N}$ $C=O$ and $O-C=O$ respectively.

Table IV.- Pure PVA XPS spectrum.

Table V.- PVA XPS spectrum according to Rogojanu et al..

Table VI.- Isoelectric points.

Table VII.- Fractal dimension and roughness (measured from $1 \times 1 \mu \mathrm{m}$ ).

Table VIII.- Apparent and material contact angles.

Table IX.- Pure water permeability $L_{w}$ and porosity $\Theta$.

Table X.- Summary of surface characteristics of the AFC membranes studied here.

\section{Figure Captions}

Fig. 1.- Scheme of the permeation plant used.

Fig. 2.- $O$ versus $N_{2}$ content of some RO and NF polyamide-like membranes taken from literature (a). Our membranes (large blue circles) and others are shown too (b). For more details, see the text.

Fig. 3.- Polypiperazinamide, PVA and some of the usual crosslinkers.

Fig. 4.- Peaks fitted into C1s, O1s and N1S XPS principal peaks.

Fig. 5.- Zeta potential versus $\mathrm{pH}$ of the three membranes studied as a function of $\mathrm{pH}$.

Fig. 6.- 3D AFM images of the three membranes studied here.

Fig. 7.- Pore size distribution of the three membranes studied obtained from Image analysis of AFM pictures.

Fig. 8.- Observed retention of the different ions through the three membranes studied.

Fig. 9.- True retention of the different ions through the three membranes studied. 